\title{
Effect of heavy metals soil contamination on the oncological diseases rate
}

\author{
I. P. Suhanova, S. P. Sonko, O. V. Vasylenko, O. V. Nikitina, A. V. Balabak*, \\ M. A. Shchetyna, I. M. Hurskyi, N. O. Shevchenko, L. V. Soroka, N. V. Nechyporenko
}

\author{
Uman National University of Horticulture (Uman), \\ 1 Instytutska St, Cherkasy region, Uman, 20305, Ukraine \\ Corresponding author E-mail: a.v.balabak@ukr.net
}

Received: 28.10.2020. Accepted: 28.11.2020

\begin{abstract}
We studied the interrelation between the population health and content of heavy metals in the soils of urban ecosystems. We researched the situation in the city of Uman, Cherkasy region (Ukraine), and determined the links between the ecological quality of the urban environment and the occurrence of ecologically dependent diseases (oncopathology) in the old industrial region (Kryvyi Rih iron-ore basin). We found that the indicators did not exceed the MPC using spectral analysis of the gross content of Cu and Zn, in Uman soils. Spectral analysis of the content of mobile forms of heavy metals in the city soils was performed since mobile forms of heavy metals can be assimilated by plants and subsequently enter the human body and the abiotic component of the ecosystem of extraordinary danger to living organisms. We registered that $\mathrm{Ni}$ and $\mathrm{Pb}$ content significantly exceeded the MPC, especially in the city areas with heavy traffic. Correlation analysis showed a correlation of low and medium level $(r=0.40-0.52)$ between the content of mobile forms of heavy metals and the rate of oncological diseases. The correlation for $\mathrm{Pb}$ and $\mathrm{Ni}$, the content of which significantly exceeded the MPC, was 0.40 and 0.49 , respectively. Thus, we concluded that heavy metals could be a dangerous factor in the territory of Uman.
\end{abstract}

Key words: heavy metals; gross content; content of movable connections; urban ecosystem; ecologically specified diseases; oncopathology

\section{Introduction}

The content of heavy metals in the soils of ecological systems can reflect the degree of their load on their other components (Jarup, 2003). In the case of urban ecosystems, where the transfer of various types of environmental pollutants to the human body through trophic chains is virtually impossible, soil toxicants' diagnosis will provide a relatively clear picture of the ecological state of air example (Alloway, 2013).

The stability of metals in the environment and their inclusion in the cycle of substances (solubility in precipitation, ability to sorb by soils, bottom sediments, and assimilation by plants) leads to their gradual accumulation in the trophic chains. However, according to the WHO (Human Exposure Assessment, 2000), acute metal poisoning is quite rare nowadays, so the influence of small doses of their compounds on the organism, especially the long-term effects of such influence (Reena et al., 2011). Thus, a significant excess of their number can lead to various diseases (Ljung et al., 2006).

The analysis of cause-and-effect relations between the state of human health and environmental factors determines based on the problems of causality in pathology, on the accumulated knowledge about the individual diseases. Moreover, the population's health is somewhat dependent on the degree of adaptation to the environment, and diseases are considered an element of the ecosystem (Semenova, 2010; Sonko et al., 2012; Patz, 1996). The theory of homeostasis (self-regulation) is based on the organism's theory of interaction with the environment.

A specific human state, formed under the influence of a complex of adverse environmental factors, called anthropoecological stress, which precedes pathology development, is distinguished (Tymchenko et al., 2000). It is considered that about 10,000 diseases and more than 100,000 disease symptoms are initiated by stress (Zherbo, 2002). Stress accelerates the aging process. For example, the "response of the organism" to the level of atmospheric and soil pollution in descending order are immunological reactivity, acute respiratory diseases of allergic nature, and deviations from the norm of the functional and physiological indicators. They are an abnormality of harmonious physical development, anemia, decreased ventilation function of the lungs, growth of chronic diseases; and increasing the frequency of congenital anomalies, tumors, blood diseases, and circulatory systems that respond to the quality of the living environment (Shyjan, 2011).

The hematopoietic, cardiovascular, respiratory, central nervous, and urogenital systems were the most sensitive to environmental factors (Kiku, 2010; Kunzli \& Tager, 2005). The issue of environmentally conditioned diseases naturally arises when studying the interrelation between population and environmental factors. There are various aspects. They also talk about the diseases of ecological etiology and distinguish ecologically dependent diseases and ecologically caused diseases (Suhoveeva, 2008). Sometimes the term "indicator presumably environmental disease" is used, which means the incidence among the population of a particular area, which is related to the action of harmful local factors, the intensity of which has increased significantly compared to those of the past 5-10 years (Zerbino, 2002). The term "specific environmental disease" means a disease observed in the population of a particular area, is conclusively connected with the harmful factor of habitat, and that is characteristic by symptoms and syndromes for the action of this causative factor (Zerbino, 2002).

Oncological diseases (or neoplasms) among the ecologically dependent (it is more appropriate to use the term "environmentally conditioned") are distinguished (Gasangadjieva, 2010). Some information sources indicate a direct connection between heavy 
metals and the development of such pathologies (Tymchenko et al., 2000). However, under the condition of their transition to the category of "ecotoxicants" that is in quantities exceeding the MPC, these chemical elements can indirectly cause the development of severe diseases through the impact on the systems of the homeostasis support of the human body. These are the systems of specific protection and systems of nonspecific resistance (Jarup, 2003). In this paper, we consider heavy metals in quantities exceeding the MPC as the factors of so-called environmentally dependent diseases.

The purpose of the research was to identify the soil contamination of the city of Uman with heavy metals and establish the dependence between the content of mobile forms of heavy metals in the soil and the rate of oncology disease.

\section{Materials and Methods}

Choosing soil samplings was performed within the city medical districts (Fig. 1) according to the generally accepted method (Alekseenko et al., 2011; Djuvelikjan et al., 2009). Simultaneously, a set of points was applied to the cartographic basis, within which soil samples were taken by the route method. The depth of samples was $20-30 \mathrm{~cm}$.

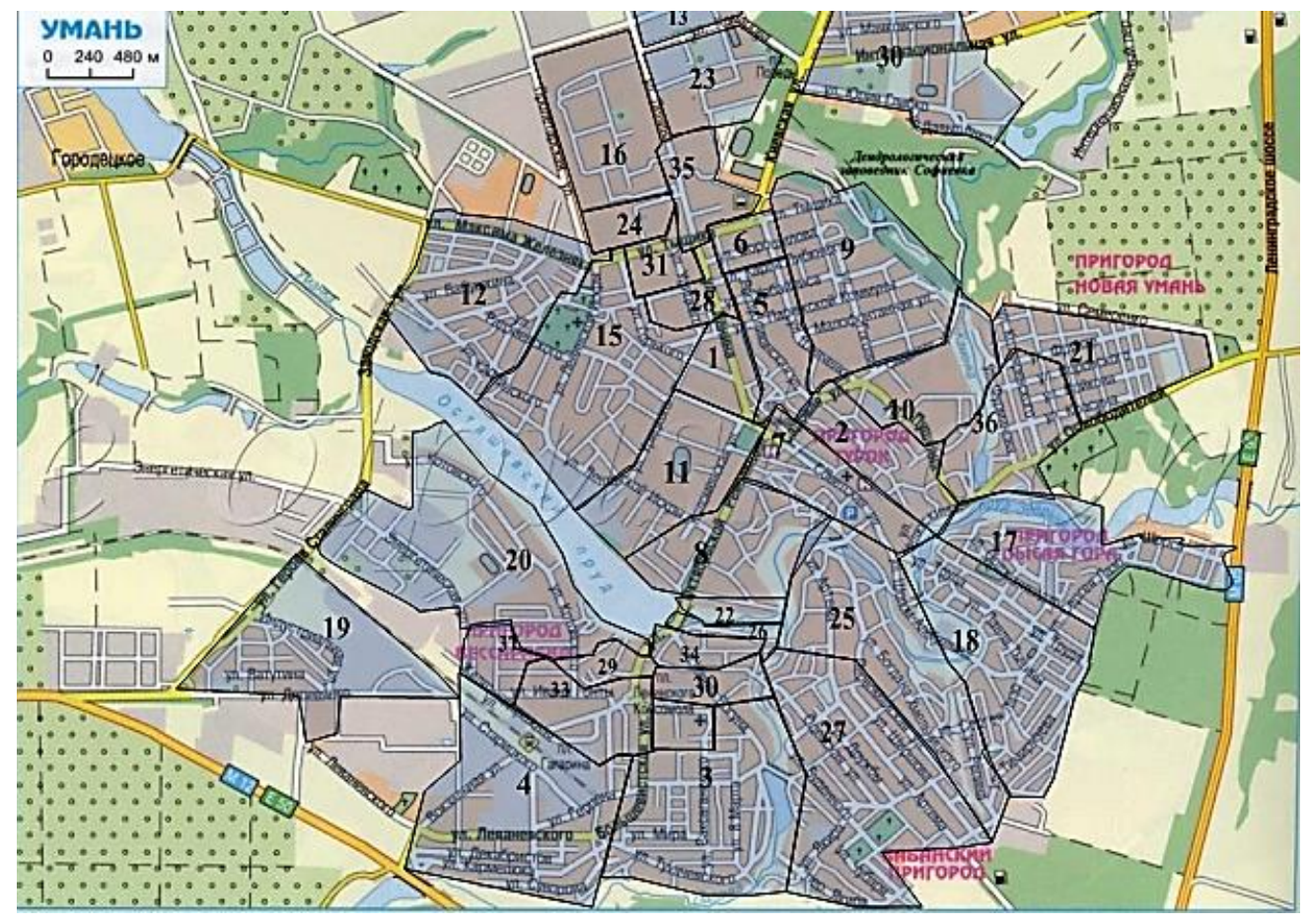

Fig. 1. Map of Uman city roads and distribution the territory of the city by medical districts (within one precinct with 2,000 inhabitants).

Determination of the gross content of heavy metals in the soil samples was performed by X-ray fluorescence method and infrared spectral analysis in the National Research Center "Sokolovsky Institute of Soil Science and Agrochemistry" using appropriate spectrometers from Soil Cares company in the Laboratory of Instrumental Methods of Soil Studies.

Determination of the content of mobile compounds of lead, cadmium, cobalt, copper, iron, manganese, zinc, nickel, and chromium in soil samples (buffer ammonium acetate extract with a pH of 4.8) was performed by atomic-and-absorption spectrophotometry in the Laboratory of Instrumental Methods of Soil Studies (certificate on attestation No. 01-0105/2017 valid until 31.07.2020) of the National Research Center "Sokolovsky Institute of Soil Science and Agrochemistry".

The rate of population oncopathology was determined as a percentage from the total number of registered diseases.

\section{Results and Discussion}

As a result of studying the gross content of heavy metals in Uman city's soils (Fig. 2), it was found that these indicators did not exceed the MAC and could only indicate certain tendencies in the intensity of soil contamination in the city with heavy metals. 


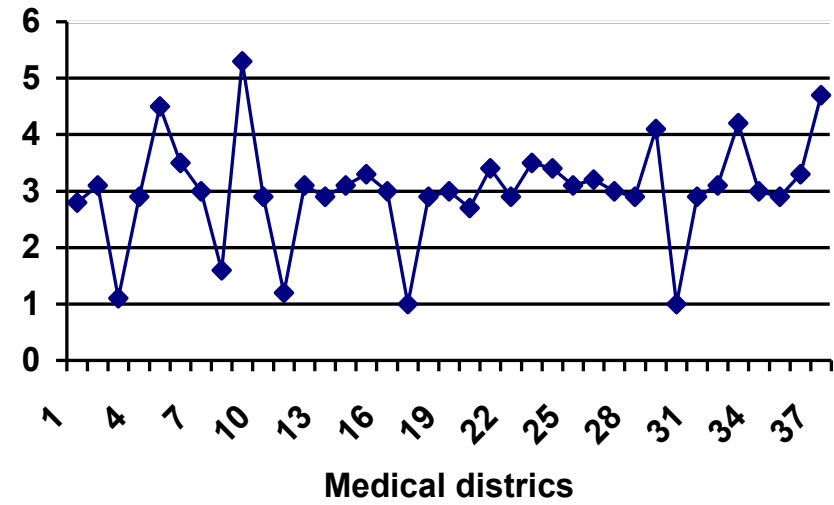

$\rightarrow$ Contents $\mathrm{Cu}(\mathrm{MAC} 300)$

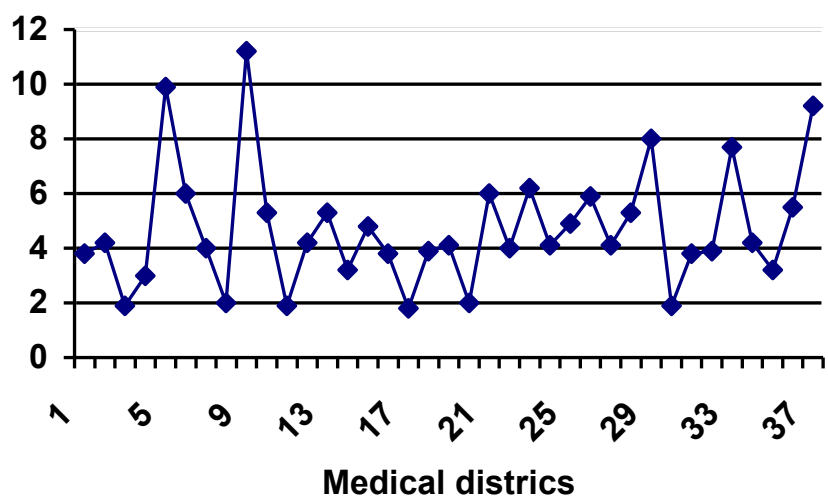

$\multimap$ Contents Zn (MAC 100)

Fig. 2. The gross content of $\mathrm{Cu}$ and $\mathrm{Zn}$ in the soils of Uman city.

It should be added that the increased content of sedentary compounds of heavy metals in soils is not a direct threat to living organisms. Plants and, accordingly, do not assimilate such forms and are not transported by food chains. A dangerous situation arises when metals in the soil are part of mobile forms of compounds that biota can directly absorb. When studying the content of mobile forms of heavy metals in Uman city's soils, it was found that $\mathrm{Cu}$ and $\mathrm{Zn}$ did not exceed the MAC (Fig. 3). However, in many cases, this indicator was significantly higher than the MAC (P>0.05) for Ni and Pb (Fig. 4).

We observed this especially within medical districts of $4,14,16,19,34,37$, and 38 . Thus, the nickel content was 5.53-5.61 at the MAC of $4 \mathrm{mg} / \mathrm{kg}$. Moreover, the lead content was $6.96-8.97$ at the MAC of $2 \mathrm{mg} / \mathrm{kg}$. These city districts were mainly characterized by the busiest traffic flow. The radial-and-circular structure of the territory in the city development plan of Uman city can be observed, and some main streets are a continuation of the two main highways. The primary external road connections of Uman city within Ukraine are provided by a net of roads of state importance: the international highway of E-95 and M-12, which explains the high intensity of traffic.

In general, Uman city streets, where the largest number of vehicles go, are characterized by multi-store buildings. The predominant type of transport is cars, a relatively small number of trucks is observed on the city's central streets. Traffic due to many cars in the central areas is somewhat slowed down, which causes significant emissions of harmful substances into the atmosphere. Accordingly, the largest number of emissions is observed near the traffic lights and low-quality roads. Just as lead is the priority pollutant during petrol combustion, and nickel is the priority pollutant for diesel fuel, so the share of the impact of these elements on the general background of pollution in medical districts is the largest. About $25-75 \%$ of Pb emissions depended on traffic conditions and entered the atmosphere, and most of it was deposited on the ground when the car is moving (Fan et al., 2012).

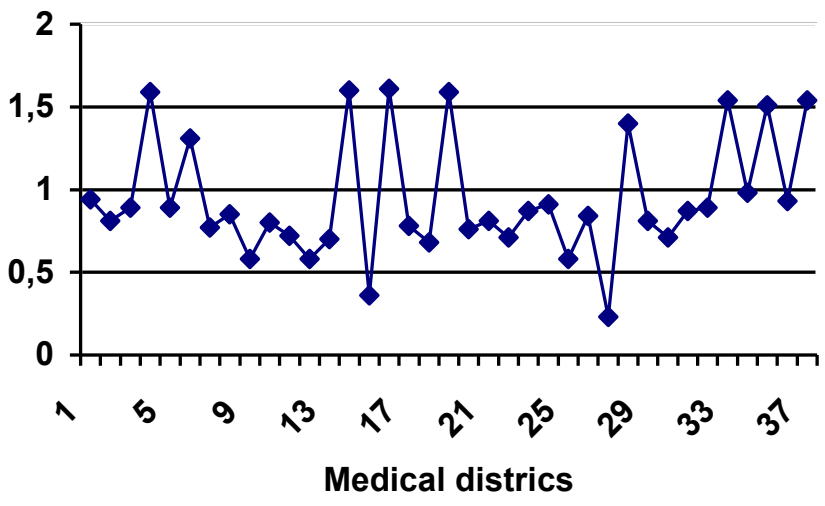

$\multimap$ Contents $\mathrm{Cu}(\mathrm{MAC} 3,0)$

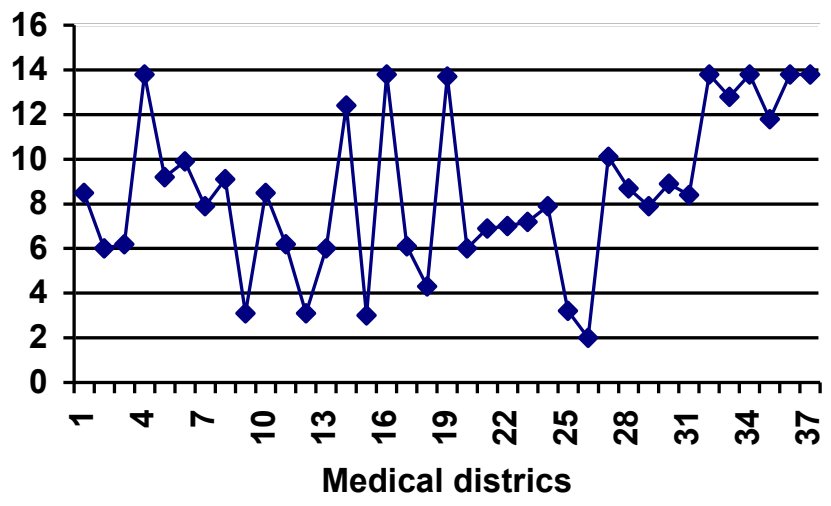

$\longrightarrow$ Contents Zn (MAC 25)

Fig. 3. The content of $\mathrm{Cu}$ and $\mathrm{Zn}$ mobile forms in the soils of Uman city.

We used quality scales to consider the difficulty of obtaining a unified indicator for all heavy metals under study. Complex probable risks of developing ecologically conditioned pathologies in the areas with a high content of mobile compounds of these trace elements were estimated according to it by a 5-point scale (Fig. 5). 


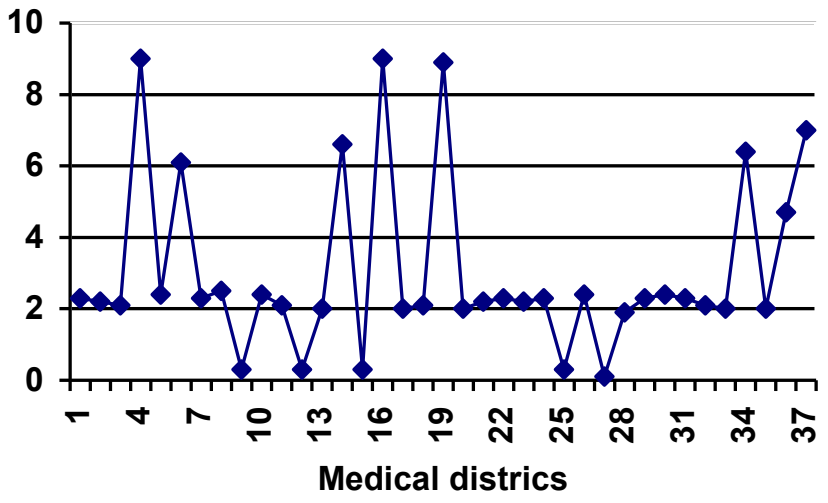

$\rightarrow$ Contents $\mathrm{Pb}(\mathrm{MAC} 2,0)$

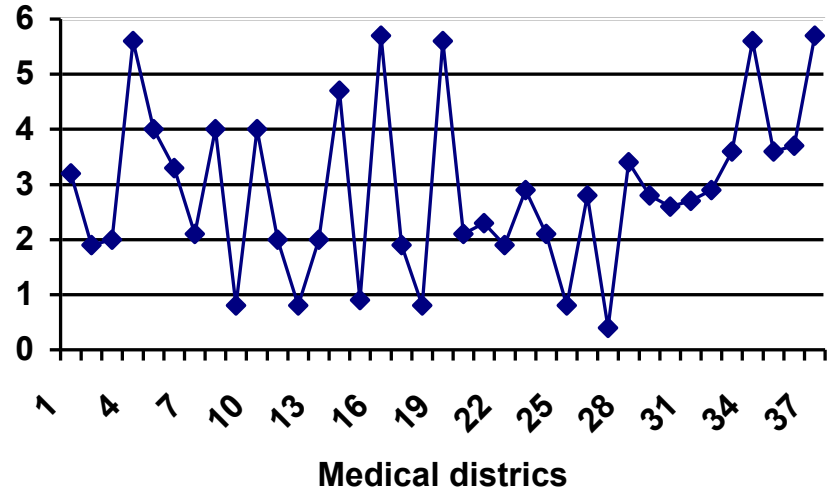

$\rightarrow$ Contents Ni (MAC 4,0)

Fig. 4. The content of $\mathrm{Ni}$ and $\mathrm{Pb}$ mobile forms in the soils of Uman city.
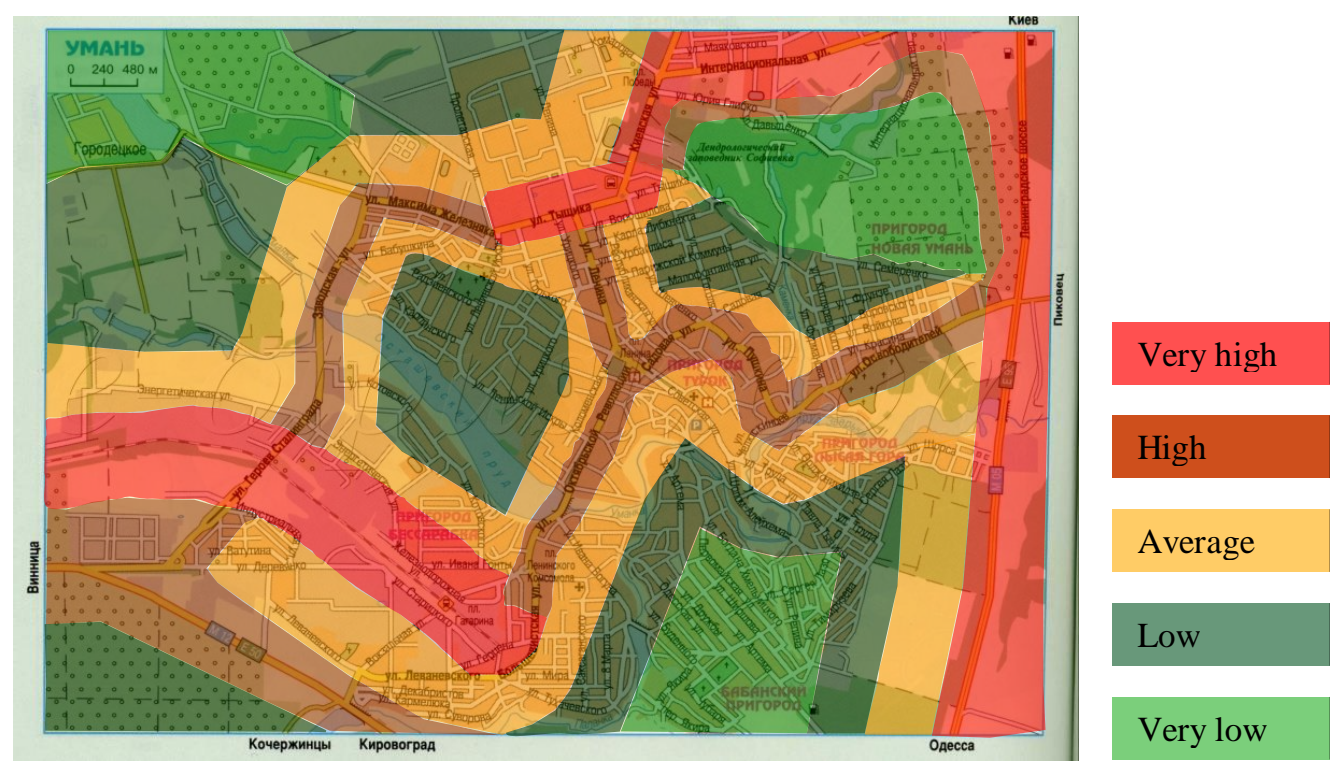

Fig. 5. Heavy metals' contamination in Uman soils.

Regarding the rate of oncological diseases of the population, today, the mortality from these pathologies ranks second place in Ukraine and the world after cardiovascular diseases such as heart attacks and blood-strokes. Every sixth woman and every fourth man is at risk (Fig. 6) in Uman city. However, the correlation analysis showed a medium correlation $(r=0.40-0.52)$ between the content of mobile forms of heavy metals and the rate of oncological diseases. The correlation for $\mathrm{Pb}$ and $\mathrm{Ni}$, the content of which significantly exceeded the MPC, was 0.40 and 0.49 , respectively, which allows us to assume the indirect effect of heavy metals on the development of neoplasms.

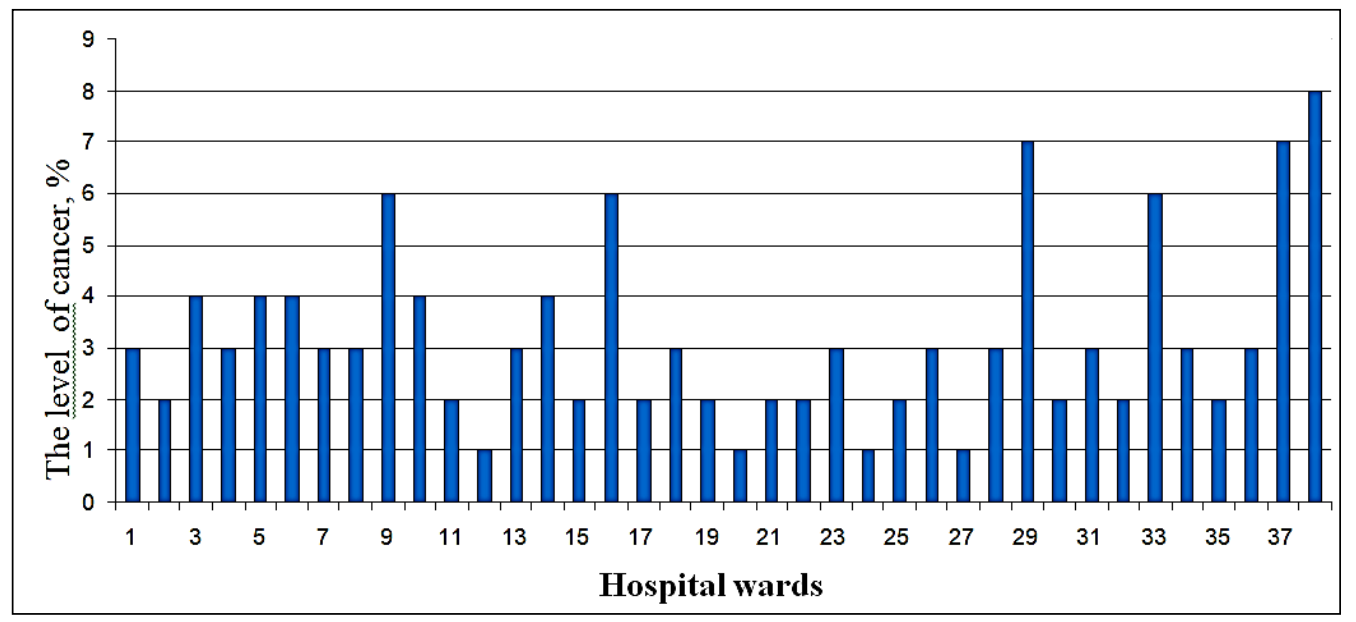

Fig. 6. The rate of oncological incidence in Uman city.

Lead affects the hematopoietic and nervous systems, gastrointestinal tract, and kidneys. It causes anemia, as it is included in the chain of biosynthesis and shortens erythrocytes' life; it also causes encephalopathy - decreasing mental properties can cause 
hyperkinetic or aggressive conditions, dyspepsia, nephropathy, gastrointestinal disorders, and colic. All these manifestations of the adverse effects of lead on the human body can indirectly cause the appearance of neoplasms. Lead has also been directly connected with cancer of the stomach, intestines, and kidneys (Tymchenko et al., 2000).

Nickel is also a very toxic element, namely its soluble compounds, which most often enter the body with drinking water. It has a toxic effect on metalloenzyme activity, disrupts the synthesis of protein, DNA, and RNA. Nickel poisoning can lead to serious respiratory diseases and death (Pope et al., 2009). The consequences of poisoning by carbonyl, the most toxic compound of nickel, are dizziness, headache, nausea, insomnia, vomiting, irritability, viral pneumonia, and pulmonary symptoms. That is especially relevant. Functional disorders in the kidneys, liver, spleen, adrenal glands, and CNS are recorded. In many countries, about $1 \%$ of the male population and $10 \%$ of the female population are quite sensitive to nickel influence. About $40-50 \%$ of people have vesicular eczema of the hands, which in some cases can lead to loss of labor capacity (Savolainen, 1996). There is some evidence of the carcinogenicity of nickel sulfate for people and nickel oxides and sulfide mixtures found under nickel recycling. Metallic nickel and nickel alloy have been studied little concerning their carcinogenicity.

In general, some studies mentioned a small number of disease types that are reliably caused by environmental pollution. These were just three pathological conditions, the prevalence of which is different in dirty and clean areas: allergic diseases, especially atypical dermatitis, and recurrent bronchitis and iron deficiency anemia (Prüss-Üstün et al., 2006). However, some works studied the spatial features of the spread of environmentally dependent pathology in old industrial development (Shmatkov et al., 2009). Thus, a close connection between the type and mass character of the appearing disease with the peculiarities of industrial and residential development within Kryvyi Rih (Ukraine) was established by GIS-analysis (Sonko et al., 2015). Herewith, environmental factors might spatially "overlap" with social factors acting multiplicatively in this case and giving a completely different negative quality. Thus, when analyzing the incidence of "environmental" and "social" diseases, their high spatial coincidence was noted in most medical districts. There was a decline in the citywide dynamics of incidence in diseases associated mainly with air quality deterioration, including neoplasms, various allergic diseases, vegetative-vascular dystonia, bronchial asthma, bronchitis, various diseases of the upper respiratory tract. Simultaneously, the intensity of diseases (per 1000 inhabitants) tended to decrease in the south-north direction (as it moves away from the southern industrial hub).

\section{Conclusion}

We found that the $\mathrm{Cn}$ and $\mathrm{Zn}$ contamination did not exceed the MPC in Uman city's soils. We also registered that Ni and Pb content significantly exceeded the MPC, especially in the city areas with heavy traffic. Correlation analysis showed a low-medium correlation $(r=0.40-0.52)$ between the mobile forms of heavy metals content and the rate of oncological diseases. The correlations between $\mathrm{Pb}$ and $\mathrm{Ni}$ and oncological disease rate were 0.40 and 0.49 , respectively.

Thus, we supposed to have the danger of pollution in the Uman city territory, Cherkasy region, as we registered that the concentration of $\mathrm{Ni}$ and $\mathrm{Pb}$ exceeded the maximum allowable limit by 1.5 and 4 times, respectively that can lead to the development of oncological diseases within the city and surrounding areas.

\section{References}

Alekseenko, V.A., Suvorinov, A.V., Vlasova, E.V. (2011). Metals in the environment: assessment of ecological and geochemical changes. Logos, Moscow (in Russian).

Alloway, B. J. (2013). Sources of heavy metals and metalloids in soils. Heavy metals in soils (Dordrecht: Springer Netherlands), 1150.

Djuvelikjan, H.A., Zheglov, D.I., Gorbunova, N.S. (2009). Soil contamination with heavy metals. Methods of control and regulation of contaminated soils. Voronezh.

Fan, Zhang, Xuedong, Yan, Chen, Zeng (2012). Influence of traffic activity on heavy metal concentrations of roadside farmland soil in mountainous areas. Int J Environ Res Public Health, 9(5), 1715-1731. doi: 10.3390/ijerph9051715.

Gasangadjieva, A.G. (2010). Ecological and geographical principles of predicting the incidence of malignant neoplasms in the population of the Republic of Dagestan. Mahachkala.

Glazovskaja, M.A. (2007). Geochemistry of natural and technogenic landscapes. (Landscape-geochemical processes). Moscow.

Human Exposure Assessment. (2000). Environmental Health Criteria. Geneva. WHO/IPCS.

Jarup, L. (2003). Hazards of heavy metal contamination December British. Medical Bulletin, 68(1), 167-182. doi: $10.1093 / \mathrm{bmb} / \mathrm{ldg} 032$.

Kiku, P. F. (2010). Socio-hygienic analysis of the impact of environmental factors on distribution of ecology-dependent diseases. Bulletin SB RAMS, 30(1), 31-56.

Ljung, K., Selinus, O., Otabbong, E. (2006). Metals in soils of children's urban environments in the small northern European city of Uppsala. Science of the Total Environment, 366 (2-3), 749.

Patz, J.A. (1996). Health adaptation to climate change: need for far-sighted, integrated approaches. In: Adapting to climate change: an international perspective. Smith, J. (Ed.). New York, USA, Springer-Verlag.

Pope, C.A. 3rd, Ezzati, M., Dockery, D.W. (2009). Fine-particulate air pollution and life expectancy in the United States. N Engl J Med, 360, 376-86.

Prüss-Üstün, A., Corvalán, C. (2006). Preventing disease through healthy environments. towards an estimate of the environmental burden of disease. Geneva, Switzerland: World Health Organization (WHO) Press.

Reena Singh, Neetu Gautam, Anurag Mishra (2011). Heavy metals and living systems: An overview Indian J Pharmacol, 43(3), 246253. doi: $10.4103 / 0253-7613.81505$.

Savolainen, H. (1996). Biochemical and clinical aspects of nickel toxicity. Rev Environ Health, 11, 167-73.

Semenova, Z. A. (2010). Medical geography - the science of man, nature and society. The theory of socio-economic geography: current state and development prospects. Rostov-na-Donu (in Russian).

Shyjan, D.V. (2011). Public geographical study of the incidence of ecologically dependent diseases in the population of Kryvbas. Bulletin of the Donetsk Institute of Social Education: Geography Series, 7, 132-135 (in Ukrainian).

Shmatkov, G.G., Oksamytnyi, A.F., Nikolaeva, I.N. (2009). Environmental problems of ensuring the safe life of technogenically loaded regions (on the example of the Dnipropetrovsk region). Ecology and nature management, 12, $42-47$ (in Ukrainian). 
Sonko, S.P., Shiyan, D.V. (2015). The study of population morbidity based on the spatial diffuse models in old industrial region of Krivbass. Journal of Socio-Economic Geography: Interregional Collection of Scientific Papers, 18(1), 63-70 (in Ukrainian).

Sonko, S.P., Suhanova, I.P., Golubkina, O.M. (2012). The level of ecologically determined morbidity of the population as a bioindicator of the state of the environment. Proceed. Reg. Sc. Conf. "Actual ecological and agrobiological problems of the Middle Dnieper in the context of sustainable development", 195-198 (in Ukrainian).

Suhoveeva, A. B. (2008). Geo-ecological and geochemical peculiarities of the territory and their impact on health (for example, the Jewish Autonomous region). Ecology and rational nature management, 2, 93-95 (in Russian).

Tymchenko, O.I., Serduk, A.M., Turos, O.I., Omelchenko, E.M. (2000). Methodology for assessing the impact of environmental factors on public health: the choice of research type and indicators. Journal of the Academy of Medical Sciences of Ukraine, 6(3), 566-574 (in Ukrainian).

Zerbino, D. D. (2002). Environmental pathology and environmental diseases: new challenges of medicine (for example, coronary heart disease). Environment and health, 1, 27-38.

Zherbo, A.P. (2002). Environment and health: approaches to risk assessment. St. Petersburg.

\section{Citation:}

Suhanova I. P., Sonko S. P., Vasylenko O. V., Shchetyna M. A., Nikitina O. V., Nechyporenko N. V., Balabak A. V., Soroka L. V., Shevchenko N. O., Hurskyi I. M. (2020). Effect of heavy metals contamination in soil on the level of oncological diseases. Ukrainian Journal of Ecology, 1066), 1-5.

(cc) $\mathrm{EY}$ This work is licensed under a Creative Commons Attribution 4.0. License 